\title{
Microbial Contamination of Drinking Water Supplied by Private Wells after Hurricane Harvey
}

\author{
Kelsey J. Pieper,* C. Nathan Jones, William J. Rhoads,* McNamara Rome, Drew M. Gholson, \\ Adrienne Katner, Diane E. Boellstorff, and R. Edward Beighley
}

Cite This: Environ. Sci. Technol. 2021, 55, 8382-8392

Read Online

\section{ACCESS 1}

Џll Metrics \& More

Article Recommendations

Supporting Information

ABSTRACT: Hurricane Hurricane Harvey made landfall on the Texas Gulf Coast on August 25, 2017, as a Category 4 hurricane and caused widespread flooding. We explored spatial and temporal distributions of well testing and contamination rates; relationships between contamination and system characteristics and recovery behaviors; and efficacy of mitigation strategies. We estimated that over 500000 well users $(\sim 130000$ to 260000 wells $)$ may have been affected, but only around 15000 well users $(\sim 3800$ to 7500 wells) had inundated systems based on inundation maps. Local health departments and our team sampled 8822 wells in 44 counties in the 10 months that followed. Total coliform occurrence was 1.5 times and Escherichia coli was 2.8 times higher after
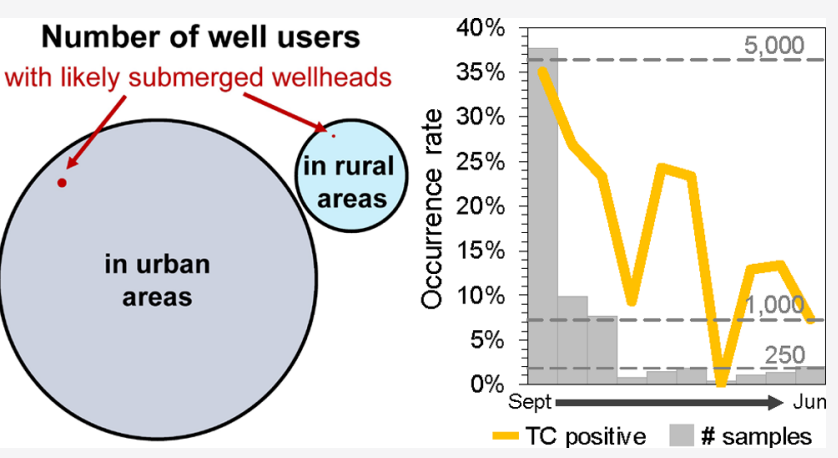

Hurricane Harvey compared to baseline levels. Microbial contamination was more likely (1.7-2.5 times higher) when wells were inundated and/or residents felt their water was unsafe. Although more wells in urban counties were affected, E. coli rates were higher in wells in rural counties. Disinfection did not always eliminate contamination, highlighting concerns about the implementation and efficacy of chlorination procedures. Despite this extensive well testing conducted after Hurricane Harvey, we estimate that only $4.1 \%$ of potentially affected wells were tested, underscoring the magnitude of recovery assistance needed to assist well users after flooding events.

KEYWORDS: private wells, wellwater, hurricane recovery, drinking water, microbial contamination

\section{INTRODUCTION}

Hurricane Harvey made landfall on the Texas Gulf Coast on August 25, 2017, as a Category 4 hurricane, causing 60 counties to declare a state of emergency due to $1.5-3.7 \mathrm{~m}$ (5$12 \mathrm{ft}$.) storm surges, $209+\mathrm{kph}(130+\mathrm{mph})$ winds, and nearly $1.4 \mathrm{~m}$ (4.5 ft.) of rainfall. ${ }^{1,2}$ The National Ground Water Association (NGWA) estimated that the resulting widespread flooding affected 215906 private wells, ${ }^{3}$ potentially introducing waterborne contaminants into the well system. While the U.S. Environmental Protection Agency and Texas Commission on Environmental Quality rapidly assessed 2238 municipal drinking water facilities and 203 boil water notices were issued to notify customers of potential health risks, well users were solely responsible for the safety of their water. ${ }^{4,5}$ This is concerning because participation in post-flood well water stewardship activities are known to be low, ${ }^{6,7}$ and there was well-documented surface water contamination after Hurricane Harvey associated with the release of untreated and partially treated wastewater. ${ }^{8,9}$

There is a critical need to evaluate well water quality immediately after flooding events to understand how system characteristics and user behaviors influence microbial contamination rates. Drinking water contamination in flood- impacted private wells is commonly evaluated by testing for the presence of total coliform (TC) and/or Escherichia coli (EC) bacteria, which serve as indicators of surface water and fecal contamination, respectively. However, the occurrence of coliform bacteria in private wells varies substantially even under nonflooded conditions-routine state and regional surveys report TC- and EC-positive rates ranging from 1569 to $2-15 \%$, respectively. ${ }^{10-14}$ The variability in contamination rates has been attributed to factors such as geologic formations, well construction practices, and inherent limitations of grab sampling techniques. ${ }^{10,15-18}$ Although it is assumed that there is an increased incidence of microbial contamination in private wells after flooding, efforts exploring contamination mechanisms and pathways have usually occurred weeks to months after. ${ }^{6,19-23}$ Environmental factors (e.g., proximity to floodways and flood fringe) have not been

Received: December 14, 2020

Revised: May 10, 2021

Accepted: May 10, 2021

Published: May 25, 2021

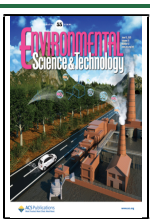




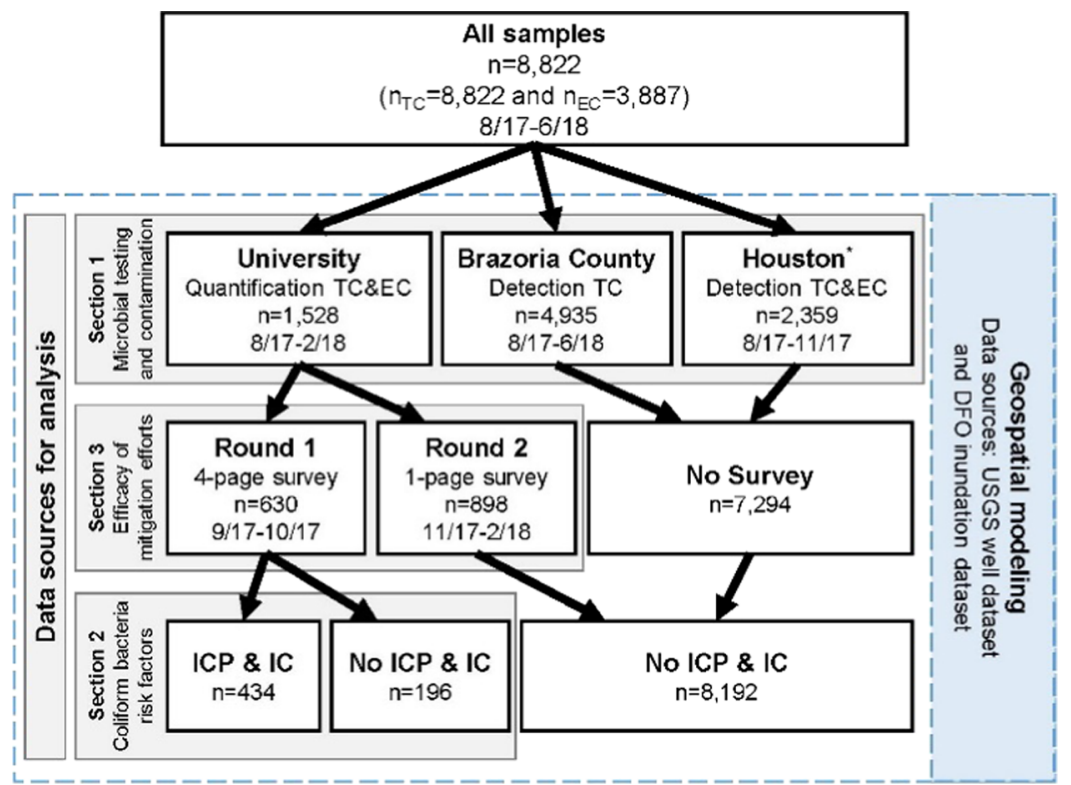

Figure 1. Summary of data sources and datasets used in study analysis. The data sources used in our analysis (gray boxes): (1) Section 1: all datasets were used to evaluate testing and contamination rates; (2) Section 3: Rounds 1 and 2 of the University dataset were used to evaluate the efficacy of mitigation efforts; and (3) Section 2: Round 1 of the University dataset was used to evaluate coliform risk factors. Geospatial modeling (blue box) was used in all analyses and was performed using the USGS well dataset ${ }^{32}$ and DFO inundation dataset ${ }^{a} *$ Samples collected in Harris and Fort Bend Counties were included in the Houston Health Department dataset. TC: total coliform bacteria; EC: E. coli bacteria; ICP: inductively coupled plasma-mass spectrometry. IC: ion chromatography; USGS: US Geological Survey; DFO: Dartmouth Flood Observatory. ${ }^{33}$

observed to be strongly associated with contamination, leading researchers to suggest that individual well factors (e.g., construction practices) may be more predictive of contamination. ${ }^{20}$ Moreover, there are concerns that users implementing recovery strategies (e.g., well disinfection) may not be effective. ${ }^{24,25}$

After Hurricane Harvey, an unprecedented amount of well water testing was conducted by local health departments and university researchers, as 8822 private wells in 44 counties were sampled starting within days of floodwaters receding and continuing for 10 months. In this study, we combined these testing results with publicly available geospatial data to explore whether environmental factors, well system characteristics, time of sampling, and user behaviors influenced testing and contamination rates in the aftermath of Hurricane Harvey. Post-Harvey data were used to determine: (1) the spatial and temporal extents of coliform bacteria testing and contamination rates; (2) well water usage, system characteristics, and stewardship practices that influence the likelihood of contamination; and (3) the effectiveness of mitigation strategies on restoring well water quality. Our results have implications for disaster planning, preparation, and recovery in addition to household-level outreach needs related to emergency testing and treatment strategies.

\section{METHODS}

Citizen Science Well Water Testing Campaigns. We evaluated well water data collected through two citizen science sampling platforms: (1) university researchers provided testing in multiple counties that declared a state of emergency and (2) local health departments offered testing in their localities.

University Testing. Two rounds of citizen science sampling campaigns were organized, and free well water testing was advertised through media outlets and the Texas Well Owner Network (TWON; www.twon.tamu.edu). Interested residents were given a sample kit, which contained one sampling bottle, sampling instructions, and a questionnaire. On a predetermined morning, residents were instructed to perform a $5 \mathrm{~min}$ cold water flush at a high flow rate tap (e.g., bathtub) to draw fresh water into the system, followed by a $1 \mathrm{~min}$ cold water flush at the kitchen tap. After flushing, residents filled their sampling bottle with cold water from the kitchen tap without adjusting flow (Supporting Information, Section S1). When indoor plumbing was damaged and not functioning, residents were instructed to use any working tap. Residents were also asked to complete a questionnaire. In Round 1 (September 11, 2017 to October 22, 2017; $n=630$ sampling kits; Figure 1), residents were given a four-page (33 questions) questionnaire about well and household characteristics, water use behaviors before and after the hurricane, well water maintenance and recovery strategies, and knowledge about and access to resources (Section S2). In Round 2 (November 2, 2017 to February 15, 2018; $n=898$ sampling kits) the questionnaire was reduced to one page (10 questions). As this round was supported by FEMA Region 6, only questions regarding well and household characteristics were retained (Section S3). Sampling kits were returned to the local Extension office by participants the same day the samples were collected. Samples were put on ice and transported to Virginia Tech or Texas A\&M laboratories within $24 \mathrm{~h}$ for analysis. Participation in this campaign was voluntary, and all procedures were approved by the Virginia Tech Institutional Review Board (\#16-918).

Water samples from the first 464 private wells sampled in Round 1 were processed at Virginia Tech. Most residents $(n=$ 403 ) collected $250 \mathrm{~mL}$ water samples, but a subset $(n=61)$ collected $1000 \mathrm{~mL}$ to quantify pathogens. A $120 \mathrm{~mL}$ aliquot was used for TC and EC, which were quantified using the IDEXX Colilert 2000 method (www.idexx.com, Westbrook, $\mathrm{MN}$ ). Laboratory blanks were included, and the detection limit was $1.01 \mathrm{MPN} / 100 \mathrm{~mL}$. A $15 \mathrm{~mL}$ aliquot was used for 
inorganic analysis via inductively coupled plasma-mass spectrometry per methods $3030 \mathrm{D}$ and $3125 \mathrm{~B}$ and anion analysis via ion chromatography per method $2510 .{ }^{26}$ An error in processing resulted in 30 samples not receiving inorganic or anion analysis. In October 2017, analysis transitioned to Texas A\&M, where 1,068 samples were processed for IDEXX analysis only (i.e., no ICP or IC analysis). For ease, residents were given the $120 \mathrm{~mL}$ IDEXX sampling container. Laboratory blanks were not included, but the detection limit remained at $1.01 \mathrm{MPN} / 100 \mathrm{~mL}$. Field blanks were not included in either campaign, so there was no assessment of potential contamination during our citizen science sampling. However, recent research illustrates that citizen science is a valid environmental sampling technique. ${ }^{27,28}$ In our study, participants were asked to collect samples as if they were "filling a glass of water", so any resulting contamination would likely be a valid assessment of waterborne risk. Further, our large sample size reduces the influence of random errors on statistical analysis. These factors minimize the impact of potential contamination associated with citizen collection on statistical inference.

Health Departments Testing. The Brazoria County and Houston Health Departments provided free well water testing for their residents (Figure 1). The Harris and Fort Bend County Health Departments provided testing for $\$ 16.50$ per sample, and these samples were analyzed at the Houston Health Department Environmental Microbiology Laboratory. Residents were notified about sampling opportunities by their respective health departments via press releases made available online and through news broadcasts. Interested residents picked up a sampling bottle at their health department and were instructed to collect a sample from an outside faucet closest to the wellhead after allowing the water to run 2-3 min. Residents returned samples to the lab within $24-28 \mathrm{~h}$ of collection, ensuring samples were processed within the $30 \mathrm{~h}$ hold time. In Harris and Fort Bend Counties, county personnel transported returned samples to the Houston Health Department laboratory.

Brazoria County Health Department provided sampling from August 2017 to June 2018 and analyzed 4935 samples. Water samples were analyzed for the presence of TC and EC, but only TC results were provided for this analysis. The Houston Health Department (including samples from Harris and Fort Bend Counties) provided testing from September to November 2017 and analyzed 2359 samples. Water samples were analyzed for the presence of TC and EC. Both laboratories used the IDEXX Colilert 2000 method. Testing results were shared at the zip code level to protect well user privacy.

Data Analysis. We used different combinations of data from the University and health department sampling efforts to address our three objectives (Figure 1). In addition, we coupled the well water testing datasets with publicly available geospatial data to characterize the number of private wells potentially affected and/or inundated by Hurricane Harvey. We considered private wells were "affected" by flooding when they were located with a Federal Emergency Management Agency (FEMA) declared disaster area that was designated for individual assistance and were "inundated" when wellheads were predicted to be submerged by floodwaters. ${ }^{29}$ This is a modified version of the NGWA approach, which considers private wells to be affected when their county receives at least 10 in. of rainfall. ${ }^{3}$ They estimate that up to $10 \%$ of affected private wells in a county may be inundated. ${ }^{30}$ Private wells sampled in this study were located in the Coastal Plain physiographic province, which has an aquifer system that consists of unconsolidated and semiconsolidated layers of silt, sand, and gravel. ${ }^{31}$

Section 1. Number of Well Users Potentially Affected and Inundated by Flooding. We used the USGS domestic well locations $^{32}$ (hereafter USGS well dataset) to determine where well users were located. The USGS well dataset is a national estimate based on the 1990 Census, proximity to roadways, and municipal boundaries. To estimate the number of affected well users, we paired this dataset with counties that the FEMA declared disaster areas and were designated for individual assistance. ${ }^{29}$ To estimate the number of inundated wells, we combined the USGS well dataset with remotely sensed inundation estimates. The maximum flood extent map was obtained from the Dartmouth Flood Observatory (hereafter DFO inundation dataset), which was derived from a combination of remotely sensed datasets (i.e., NASA Landsat 8, ESA Sentinel SAR, and MODIS data). To estimate the number of inundated well users in counties that declared disaster areas and were designated for individual assistance, we overlaid the USGS well dataset and DFO inundation dataset. ${ }^{33}$ Both datasets contain considerable uncertainty and lack validation, but they provide a first-order estimate of well users predicted to be inundated. Notably, a similar approach was recently used to examine spatial distribution of well users impacted by road salt contamination. ${ }^{34}$ To determine the influence of urbanization on contamination rates, data from the 2013 NCHS Urban-Rural Classification Scheme was used. ${ }^{35}$ We defined "urban" counties as counties with a metro classification (codes 1-4) and "rural" counties as counties with a micropolitan or noncore classification (codes 5-6). Test of proportions was used to determine if there were differences in TC and EC rates before and after Hurricane Harvey. All statistical analysis was performed using $\mathrm{R}$ version $3.6 .0,{ }^{36}$ using the tidyverse, sf, and raster packages. ${ }^{37-39}$

Section 2. Coliform Bacteria Risk Factors. To identify variables that may have increased the likelihood of TC and EC, we used Round 1 of the University dataset. Round 2 did not involve the corresponding chemistry analysis or the comprehensive survey and was therefore not included. Samples collected from nonpotable wells $(n=21$; e.g., irrigation wells), taps connected to public water supply $(n=1)$, and multiple samples from the same location $(n=6)$ were removed. In total, 602 private well samples were analyzed. Test of proportions and chi-squared test were used to evaluate differences based on urbanization and proximity to flooding.

Logistic regression was performed to explore variables that influenced TC and EC detection using the questionr package. ${ }^{40}$ We used single-variable logistic regression to explore the influence of survey (69 candidate explanatory variables) and water quality data (34 candidate explanatory variables) (Tables S1 and S2). For the survey data, 99.2\% of surveys were returned and individual question response rates ranged from 28.7 to $98.7 \%$ (median of $95.3 \%$ ). Only one variable (installation of acid neutralizer) had all "no" responses, so 68 explanatory variables were included. For the water quality data, the 434 water samples that received IC and/or ICP analysis were used and all explanatory variables were included. Odds ratios (OR) were calculated for all regressions deemed statistically significant $(p<0.05$.)

Section 3. Efficacy of Mitigation Strategies. To evaluate well disinfection behaviors, we used Rounds 1 and 2 


\section{GEOSPATIAL MODELING DATA}

A

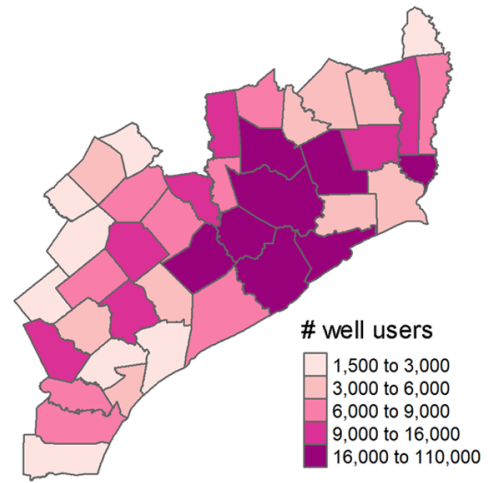

C

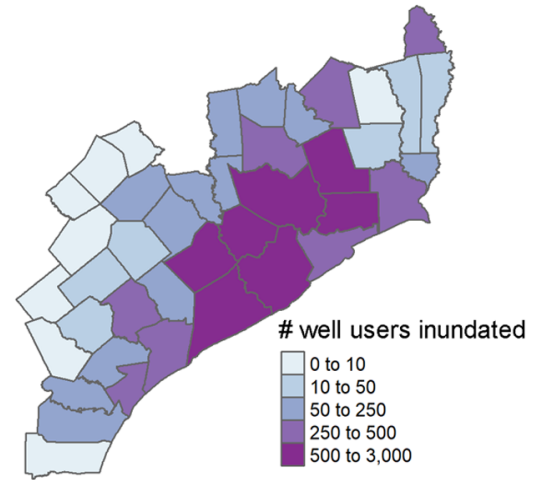

B

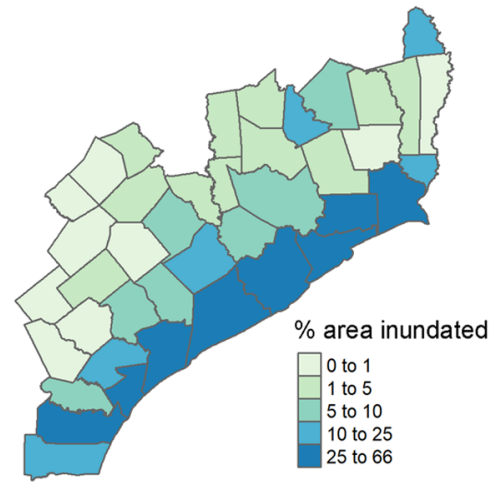

D

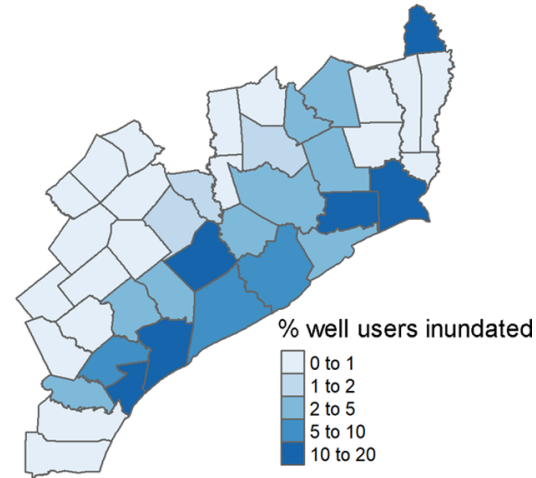

\section{CITIZEN SCIENCE SAMPLING DATA}

E

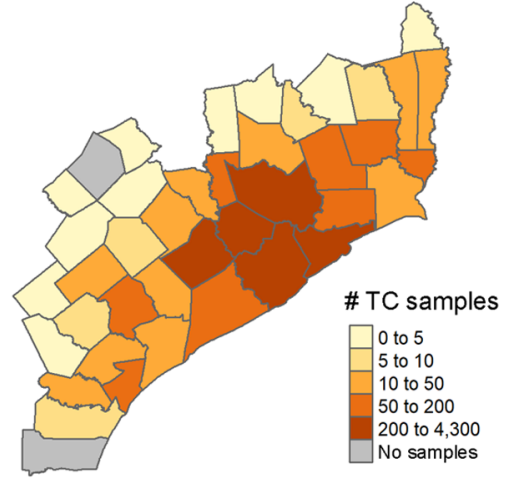

G

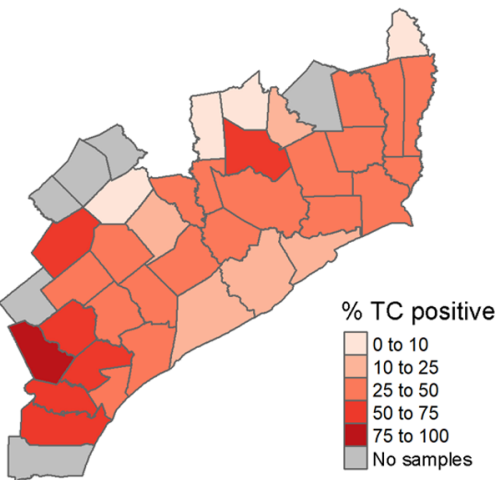

$\mathrm{F}$

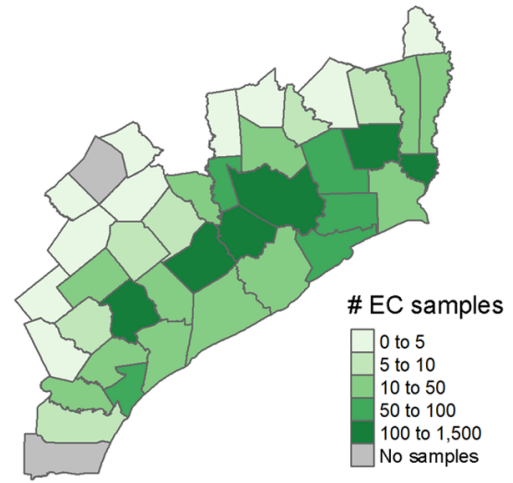

$\mathrm{H}$

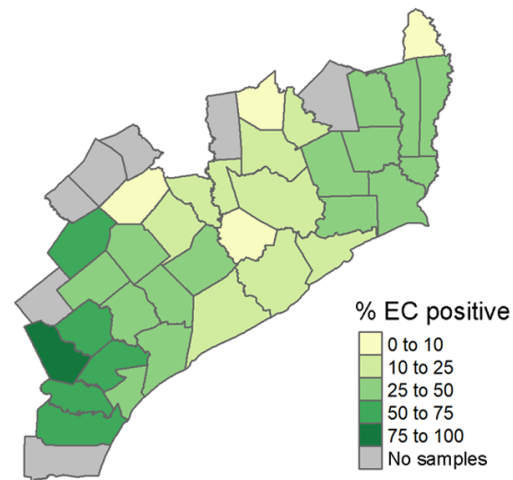

Figure 2. Geospatial modeling data illustrate the spatial extent of well populations and flood impact in counties by visualizing (A) total number of well users; (B) percent of county flooded; (C) total number of well users flooded; (D) percent of well users flooded. Well locations were derived from USGS well dataset ${ }^{32}$ and inundation from the DFO inundation dataset. ${ }^{33}$ Citizen science sampling data collected during the University and health department campaigns provided insight into testing and contamination rates by visualizing (E) total number of total coliform samples collected; (F) total number of E. coli samples collected; (G) percent of total coliform-positive samples; and (H) percent of E. coli-positive samples. TC: total coliform; EC: E. coli. 
of the University dataset. Samples collected from nonpotable wells $(n=21)$, taps connected to public water supply $(n=1)$, multiple samples from the same location $(n=93)$, and samples without TC and EC quantified $(n=8)$ were removed. In total, 1405 private well samples were analyzed. Test of proportions and Wilcoxon test were used to evaluate differences in contamination rates based on disinfection behaviors. The DFO inundation dataset was used to evaluate disinfection behaviors based on proximity to flooding.

To facilitate temporal analysis associated with natural attenuation, ${ }^{24,25}$ we estimated "weeks since peak flooding," which was calculated as the length of time between the peak flooding date for a particular county and the sampling date. Peak flooding dates were defined using the US Geological Survey (USGS) stream gage data [nwis.usgs.gov] (Table S3). We identified the date of peak flow for each stream gage of interest and then estimated the mean peak flooding date based on the stream gages within each county. If the county did not contain gages, we used the closest available gage. Among the 1405 samples, weeks since peak flooding could not be calculated for $5.2 \%$-we could not identify a stream gage $(n$ $=3$ ) or participants did not provide an address $(n=70)$. Test of proportions was used to evaluate differences in contamination rates based on weeks since peak flooding.

\section{RESULTS AND DISCUSSION}

The three datasets were used in Section 1 to evaluate testing and contamination rates, while only the University dataset was used in Sections 2 and 3 to provide a deeper understanding of the influence of household and system characteristics and mitigation strategies on coliform contamination rates.

Section 1. Impact of Hurricane Harvey on Private Wells. Thousands of Private Wells Were Likely Affected and Inundated during Hurricane Harvey. After Hurricane Harvey, 41 counties were declared a federal disaster area and designed for individual assistance (Figures $2 \mathrm{~B}$ and S1, Table S4). ${ }^{29}$ Of the 8.7 million residents in these counties, most (93.9\%) were supplied by municipal drinking water service. ${ }^{32}$ Although a small percent of the population (6.1\%), an estimated 526000 well users were likely affected by resulting flooding and associated damage (131506 to 263012 private wells assuming 2-4 users per well; Figure 2A). This estimate, derived using the USGS well dataset, is similar to the NGWA estimate of 215906 affected private wells, which assumed that private wells in counties that received at least $10 \mathrm{in}$. of rainfall were likely affected. ${ }^{3}$ We refined our estimate to determine the number of private wells that may have experienced wellhead inundation (e.g., due to storm surge, inland flooding). Coupling the USGS well dataset with the DFO inundation dataset, an estimated 3765 to 7530 private wells (used by 15060 private well users) in the 41 disaster-declared counties may have been inundated, which was only $2.9 \%$ of the affected population (Figure 2C,D).

These estimates may overestimate the number of private wells affected and inundated during Hurricane Harvey, as preventative behaviors that can reduce or even prevent contamination (e.g., extending the well casing $>12$ in. above the ground surface, installing sanitary well cap) were not considered. ${ }^{41,42}$ Given that 8822 private wells were tested after Hurricane Harvey, there was adequate capacity to test the high-risk private wells (i.e., the predicted 3765-7530 inundated private wells). However, although wellhead submersion is often considered the primary pathway, as it results in direct contamination of the well water supply, private wells can be affected by floodwater through several pathways. ${ }^{15}$ With 131506 to 263012 private wells likely affected in the 41 disaster-declared counties, there is a critical need for targeted outreach and assistance to ensure all well users have the capacity and capability to protect themselves and their families from flood-associated hazards.

Microbial Contamination of Well Water Spiked after Hurricane Harvey. A total of 8822 well water samples were collected by the organizations participating in this study (Figure 1 and Table S5). Testing efforts spanned 242 zip codes in 44 counties (Figures 2E,F and S1E,F), with most samples ( $>99 \% ; n=8710)$ collected from the 41 declared disaster counties designed for individual assistance (Tables S6 and S7). In the 10 months after Hurricane Harvey, $29.6 \%$ samples $(n=$ 2609 of 8822$)$ were positive for TC and $11.0 \%(n=427$ of 3887) were positive for EC. Coliform bacteria contamination rates were significantly higher after Hurricane Harvey (test of proportions, $p<0.001)$ relative to samples collected in the Texas Gulf Coast through TWON programming during nonflooding conditions. During nonflooding conditions, $19.6 \%(n=469)$ of samples were TC-positive and 3.9\% ( $n$ $=281$ ) were EC-positive (Table S8). These baseline contamination rates observed in 8-9 coastal counties between 2013-2017 are consistent with other coastal aquifers well testing campaigns. ${ }^{13,19}$ With TC rates 1.5 times higher and EC rates 2.8 times higher after Hurricane Harvey, there is a clear need to test (and treat) well water immediately after flooding to protect the health of those who remain reliant on or resume using their private wells.

More than half of the samples $(5181 ; 58.7 \%)$ were collected within the first month of recovery (September), and 1000+ samples were collected in each of the following 2 months. After November, only a few hundred samples were submitted monthly ( $\max$ of 274), but there was continued interest in testing through June (10 months post-Harvey). TC positivity reduced from $35.1 \%$ in September to $23.3 \%$ in November, with an average $1.9 \%$ decrease each month (Table S9). While these results highlight a general decrease in TC contamination over time, they also illustrate that the health risk is likely highest immediately following the storm event (Figure 3A). This was also observed with EC trends. EC reduced from 15.9 to $3.1 \%$ in the same timeframe, at an average reduction of $2.4 \%$ each month. These reductions could be likely associated with remediation efforts (e.g., well disinfection, flushing, or regular water use), natural attenuation of microbes within groundwater supplies or well water, and/or the decline in samples collected. $7,17,24,25$

Flood Impacts Were Not Isolated to Private Wells in Rural Counties. Private wells are often thought of as rural drinking water systems, likely attributed to the high percentage of residents in rural counties reliant on well water; however, urban counties often have substantially larger numbers of well users but well users are a smaller percentage of the total population. ${ }^{43}$ In the 41 disaster-declared counties designed for individual assistance after Hurricane Harvey, the average percent of the total population reliant on well water in rural counties was $24.5 \%$ compared to $16.1 \%$ in urban counties (Figure 4A and Table S4). However, the average percent of well users with potentially inundated systems was more similar-3.1\% of wells was inundated in rural counties vs $3.6 \%$ in urban counties. 


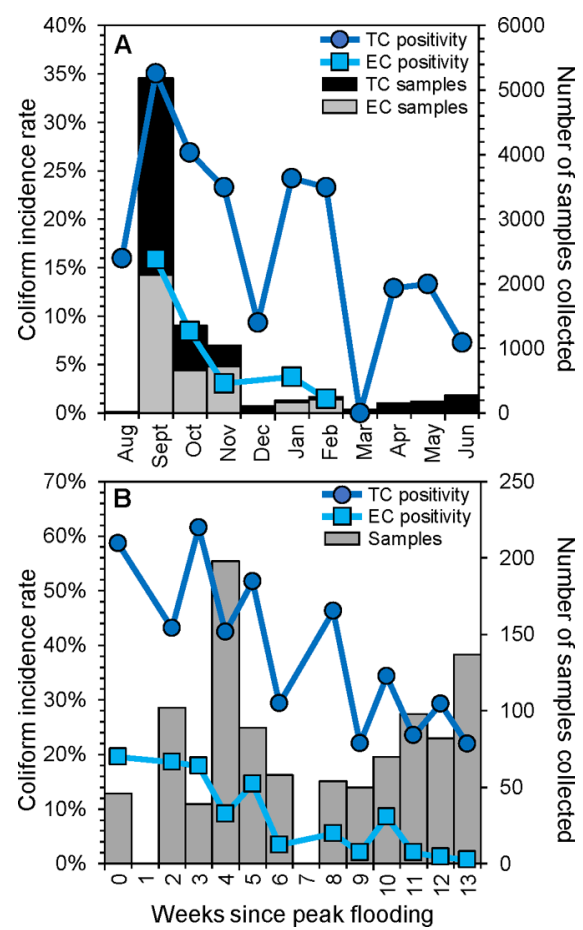

Figure 3. Number of samples and microbial contamination rates by (A) month for all three sampling campaigns and (B) weeks of since peak flooding for Rounds 1 and 2 of the University campaign through 13 weeks. TC: total coliform; EC: E. coli.

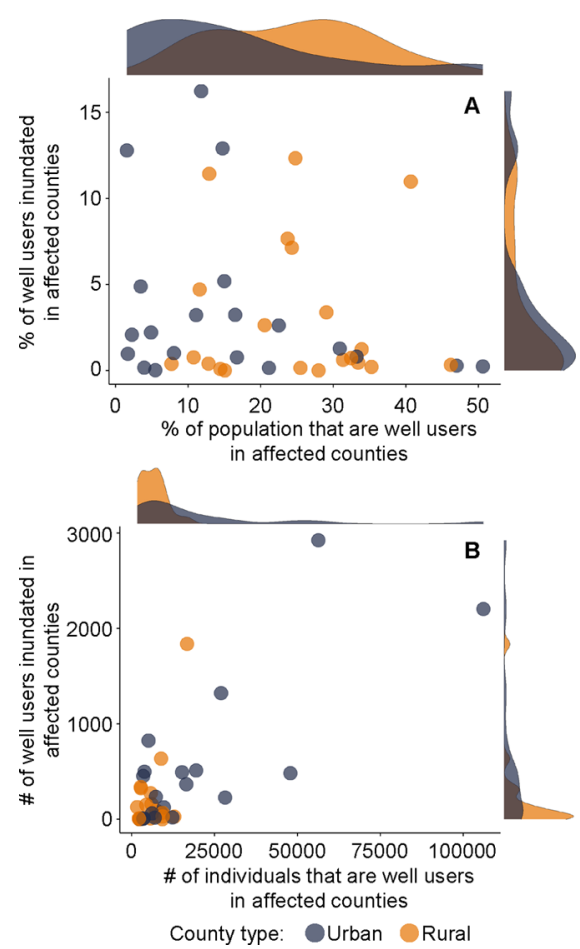

Figure 4. Comparison of affected and inundated well users across rural and urban counties derived from USGS well database and DFO inundation model: (A) percent of well users illustrates the high reliance on private wells in rural counties, while (B) total well users illustrates the large magnitude of well users in urban counties. The probability distribution urban (gray) and rural (orange) counties visualizes the distribution of well user statistics for each parameter.
When reframing the conversation to consider the number of well users potentially affected and inundated, estimates were drastically different. The average number of affected well users per county in rural counties was 6479 compared to urban counties of 19498 (Figure 4B). There were 3.0 times more affected well users per county in urban counties compared to rural counties. This trend was also evident for inundation, as an average of 542 well users per county were inundated in urban counties compared to 201 in rural counties. Thus, flood impacts were evident in both rural and urban counties, underscoring the need to address and assist well users in both settings.

When focusing on the hardest-hit well community, only $9.8 \%$ of counties $(n=4)$ had $>1000$ wells that were potentially inundated. Among these four counties, three were urban and one was rural (Figure 4B). Not surprisingly, the urban counties (Brazoria, Fort Bend, and Harris) are in the Greater Houston area and the rural county (Wharton) is within 60 miles of Houston. However, while private well contamination pathways will generally be the same in urban and rural settings, the hydrologic setting and proximity to contamination sources will likely be different. For example, areas with smaller lots (such as in urban areas) have a higher density of septic systems and likelihood of leachate contamination. ${ }^{44}$ In rural areas, the distance to a farm animal operation has been an important predictor for coliform contamination. ${ }^{12}$ To facilitate improved outreach and assistance, a deeper understanding of potential sources of flood-induced contamination and pathways based on locality is critical.

Section 2. System and Flooding Characteristics That Increased the Likelihood of Well Water Contamination. During the University Round 1 campaign (6 weeks postflooding), 602 private wells were sampled. An overview of participant, well system characteristics, and overall water quality is provided in Section S4. In brief, TC and EC rates ( 46.0 and $11.8 \%$; Figure S2) were similar to rates observed by the Houston Health Department (42.9 and 14.8\%) over the same time period, but not the Brazoria County Health Department (25.6\% TC only) (Table S5). As before, contamination rates during the Round 1 sampling varied based on county and zip code. Most participants (62.1\%; $n=$ $374)$ were from urban counties compared to $37.9 \%$ from rural counties $(n=228)$. While TC rates did not vary, EC rates were significantly lower in urban compared to rural counties (test of proportions, $p_{\mathrm{TC}}=0.44$ and $\left.p_{\mathrm{EC}}=0.02\right)$. Specifically, $\mathrm{TC}$ and EC rates were 44.7 and $9.4 \%$ in urban counties and 48.2 and $15.8 \%$ in rural counties (Figure S3).

Water and Wastewater Infrastructure Were Flooded and Damaged. More than a third of participants $(38.4 \% ; n=223$ of 581) reported having standing water in their home, with most reporting several inches $(37.2 \%)$ to a few feet $(31.8 \%)$. Almost a third of residents $(34.6 \% ; n=201)$ reported that their wellhead had been submerged, and there was a significant relationship between reporting and DFO inundation predictions $\left(\chi^{2}, p<0.001\right)$. Among the 69 participants that were within $100 \mathrm{~m}$ of a flood pixel, $89.9 \%$ reported their wellhead was submerged. Interestingly, there was a higher occurrence of wellhead submersion among residents in rural counties compared to urban counties (56.8 vs $32.5 \%$ ), which was consistent with a higher percent of well users inundated (i.e., within $100 \mathrm{~m}$ of a flood pixel) in rural counties $(34.3 \% ; n=74)$ compared to urban counties $(1.4 \% ; n=5)$. However, these statistics deviate from our predictions using USGS well and 
DFO datasets that reported the same level or greater inundation in urban counties. Differences may be attributed to potential bias in recruitment strategies and/or limitations in data resolution of large-scale databases.

Most residents reported having working water systems (97.8\%; $n=583$ of 596). However, about one in five residents (21.2\%; $n=123$ of 581$)$ reported damage to the well system and $18.1 \%(n=105$ of 581$)$ to the septic system, with $5.9 \%(n$ $=34)$ and $9.3 \%(n=54)$ residents unsure of the state of their well or septic systems, respectively. The most commonly reported problems among those reporting well damage were broken pipes in the home $(43.1 \% ; n=53)$ and electrical problems with the well pump $(36.6 \% ; n=45)$. The most commonly reported septic system damage was that floodwaters filled the septic tank $(61.0 \% ; n=64)$ or saturated the drain field $(49.5 \% ; n=51)$. Despite damage, $93.9 \%(n=559$ of 595$)$ had used their water before participating in this sampling effort. When a water use time could be determined $(n=596)$, $31.7 \%$ of participants reported using their system for less than a week and $49.0 \%$ for $2-4$ weeks (Table S10). Residents rarely had treatment devices that address microbial contamination (Section S4).

Water Safety Concerns and Flood Impacts Were Linked to Higher Rate of Contamination. Logistic regression models were used to identify factors that were predictive of coliform contamination (Figure 5, Tables S1 and S2). Significant predictors of contamination included when private wells were inundated or in close proximity to floodwaters, private wells
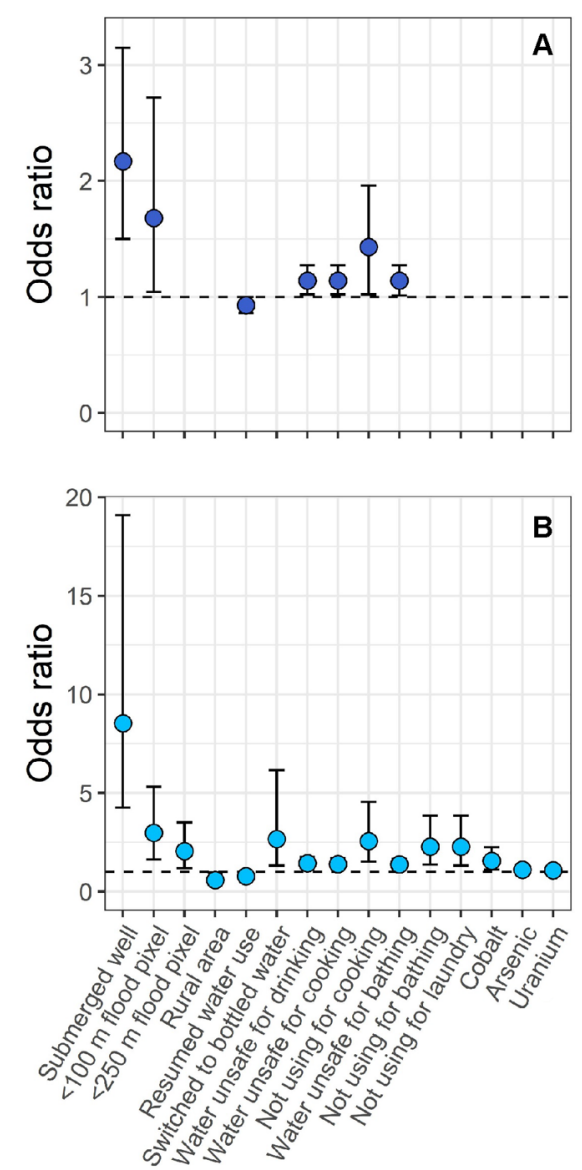

Figure 5. Odds ratios for factors that were predictive of (A) total coliform and (B) E. colicontamination. were in rural counties, and residents felt their water was unsafe. Specifically, participants who reported wellhead submersion or were within $100 \mathrm{~m}$ of the DFO mapped inundation were roughly 2 times more likely to have TC contamination (Table S11). The magnitude, significance, and number of predictive variables increased when evaluating EC contamination. EC contamination was 8.5 times more likely when participants reported wellhead submersion, 2.1-3.0 times more likely when private wells were within $100-250 \mathrm{~m}$ of the modeled inundation, and 1.7 times more likely for residents in rural counties. Perception of water safety was also significantly linked to the likelihood of contamination. There was an increased likelihood of TC and EC detection among residents who reported that they felt their water was not safe for drinking, cooking, or bathing $\left(\mathrm{OR}_{\mathrm{TC}}=1.1 ; \mathrm{OR}_{\mathrm{EC}}=1.4\right)$. In addition to the perception of water safety, the likelihood of EC contamination increased when residents reported changes in behavior. EC contamination was more likely for residents who relied on bottled water $(\mathrm{OR}=2.7)$ and had stopped using their water for cooking $(\mathrm{OR}=2.6)$ or laundry $(\mathrm{OR}=2.3)$. Of the chemical parameters measured, only cobalt, arsenic, and uranium were weakly linked $(\mathrm{OR}=1.1-1.6)$ to an increased likelihood of EC detection.

Section 3. Well Disinfection and Natural Attenuation Did Not Eliminate Microbial Contamination Universally. Well Disinfection Does Not Always Eliminate Microbial Contamination. In Rounds 1 and 2 of the University campaign, 1405 private wells participated. Among the 917 participants $(65.2 \%)$ that indicated whether their well system had been disinfected after Hurricane Harvey, only $22.4 \%(n=$ 205) had performed well disinfection. TC positivity was different based on performing disinfection-36.8\% of chlorinated wells $(n=75$ of 204$)$ and $29.2 \%$ of nonchlorinated wells $(n=208$ of 712$)$ were positive (test of proportions, $p=0.049$; Figure S4). Among TC-positive samples, median TC concentrations were also significantly lower (Wilcoxon Test, $p=0.01)$ in nonchlorinated than in chlorinated wells $(9.8$ MPN vs 27.2 MPN). In keeping, EC positivity was 3 times higher in chlorinated wells, with $11.8 \%(n=24)$ in chlorinated and $3.7 \%(n=26)$ in nonchlorinated wells $(p<0.001)$. However, median EC concentrations were not different among positive samples $(p=0.56 ; 2.0 \mathrm{MPN}$ in nonchlorinated vs 3.1 MPN in chlorinated wells). Without data documenting coliform loading before disinfection, it is not possible to determine the underlying cause for these differences. However, the higher contamination rates may indicate systems performing chlorination are much more heavily contaminated than systems that do not consider chlorination and/or hint at the potential barriers in users properly disinfecting their systems. ${ }^{45}$

Almost half of the well users within $100 \mathrm{~m}$ of modeled inundation ( $46.8 \% ; n=37$ of 79 ) chlorinated while only $25.9 \%$ within $1000 \mathrm{~m}$ chlorinated $(n=117$ of 452$)$, highlighting that private wells closer to flooding were more likely to be chlorinated (Table S12). Residents also indicated a higher rate of shock chlorination after wellhead submersion, as $47.7 \%$ of participants $(n=129$ of 272$)$ with submerged wellheads chlorinated compared to $9.5 \%(n=45$ of 476$)$ that chlorinated wellheads that were not submerged. Both well system damage and septic system damage increased the likelihood of well users chlorinating their systems (test of proportions, $p<0.001$ ). Specifically, $44.0 \%$ ( $n=81$ of 184$)$ of system were chlorinated and $12.8 \%(n=73$ of 571$)$ did not chlorinate when well damage was reported. Although the rate of chlorination was 
lower, $26.2 \%(n=44$ of 168$)$ of system were chlorinated and $10.9 \%(n=60$ of 550$)$ did not chlorinate when septic system damage was reported. Thus, proximity to flooding, wellhead submersion, and damage to infrastructure were the primary variables for participants deciding to disinfect the well system.

Among participants in Round $2(n=119)$ that chlorinated, TC and EC positivity rates were lower when professionals performed disinfection. Specifically, TC and EC positivity rates were 15.6 and $0.0 \%$ when well professionals were hired $\left(n_{\mathrm{TC}}=\right.$ 5 and $n_{\mathrm{EC}}=0$ of 32 ), compared to 29.9 and $2.3 \%$ when residents performed the disinfection $\left(n_{\mathrm{TC}}=26\right.$ and $n_{\mathrm{EC}}=2$ of $87)$. When reported, $70.0 \%$ of professionals $(n=21$ of 30$)$ and $54.5 \%$ of residents $(n=60$ of 110$)$ performed chlorination once, but the number of repeated chlorination was as high as 6 and 20 attempts. As before, drawing conclusions is challenging without data documenting coliform loading before disinfection, but these findings are in keeping with prior research highlighting concerns with residents performing chlorination procedures $^{45,46}$ and lack of scientific merit in protocols attempted by well users. ${ }^{15}$

Microbial Contamination Decreased Over Time. Resumption of water use immediately after the flood appeared to be related to likelihood of contamination (Figures $3 \mathrm{~B}$ and S5). During the height of flooding (week 0), 58.7\% of wells were TC-positive and $19.6 \%$ were EC-positive. These were significantly different than TWON baseline rates (test of proportions, $p=<0.001$ ), illustrating an increase in contamination post-Harvey. Contamination reduced over time, with TC and EC decreasing 2.7 and 1.5\% each week (Table S9), which is in keeping with trends observed in the three sampling campaign dataset (Figure 3A). Interestingly, contamination rates were elevated compared to TWON baseline data throughout the first 5 weeks post-Harvey ( $p=$ $<0.001-0.03)$. Thus, there was clearly an increased risk of microbial contamination that was evident for several weeks.

\section{IMPLICATIONS}

Private Wells Are at an Increased Risk of Fecal Contamination after Floods. We observed that TC and EC contamination rates were almost 2 and 3 times higher than background rates observed during TWON screening events and reported in other coastal area studies. ${ }^{10,11,19}$ Although we predicted more well users in urban settings to be affected and inundated after Hurricane Harvey, we observed that private wells sampled in rural counties had higher TC and EC contamination rates. This difference may be attributed to several factors including our sampling approach as we aimed to complement our testing with the Brazoria County and Houston Health Departments, which reduced participating in hardest-hit counties like Brazoria, Fort Bend, and Harris Counties; our estimates relied on the USGS well dataset, which likely overpredicts the number of urban well users; ${ }^{34}$ and there are contamination sources unique to urban and rural settings. ${ }^{12,44}$ Regardless, without well-specific baseline data for individual households, it is challenging to know if contamination observed was normal or flood-induced, as studies repeatedly report the widespread occurrence of coliform bacteria in private wells. ${ }^{10-12}$

Through the University testing, we observed that almost half of private wells had some level of impact from the flood, ranging from wellhead submersion to damage to their water and/or wastewater infrastructure. Elevated contamination rates of TC and EC existed up to 4 weeks after flooding, underscoring the need to provide immediate testing services. These findings are consistent with prior knowledge that residents who are reliant on their wells for potable water need immediate access to water testing and treatment services and/ or tools to confirm if their well water is safe to consume. ${ }^{19,20,23}$

Our study illustrates the magnitude of sampling necessary to assist well users after national disasters. These sampling efforts described in this study reached less than $5 \%$ of the well user population, yet the number of well users tested was orders of magnitude greater than previous studies. ${ }^{6,19,22,23}$ While this study provides a higher-resolution snapshot into problems immediately post-flood, our estimates of affected well-reliant households underscore the fact that flooding events are nontrivial in terms of their potential regional public health impact. These statistics raise serious concerns about the availability of and access to testing services after widespread flooding events and should stimulate discussion regarding possible changes to local, state, and federal disaster-response policies to improve support for private water well managers affected by flooding.

Data Availability and Limitations Hindered the Accurate Identification of Private Wells Affected and Inundated by Flooding. While the DFO inundation and USGS well datasets provided a back-of-the-envelope, firstorder approximation of spatial distribution of affected and inundated wells, key uncertainties limit our ability to accurately identify such private wells. First, well construction practices can reduce the risk of contamination (both direct and indirect contamination). Since 1999, the Texas Water Well Drillers and Pump Installers Administrative Rules ${ }^{47}$ have required that private wells not be constructed in flood-prone areas and the well casing should extend at least $12 \mathrm{in}$. above the land surface. If constructed in a flood-prone area, the casing must extend at least $36 \mathrm{in}$. Thus, inundation in the vicinity of a private well does not necessarily mean the system will be contaminated. Further, there is uncertainty associated with estimates of inundation extent and contamination pathways. ${ }^{48,49} \mathrm{We}$ focused on surface water inundation, which does not capture all potential contamination pathways (e.g., concentrated surface runoff or subsurface contamination $\left.{ }^{15}\right)$. Finally, incomplete accounting and mapping of private wells introduce additional uncertainty. The USGS well database used in this study is a model of potential well users based on the 1990 US Census data, and while it has been validated in California and Colorado, it has not been validated across the Gulf Coast. Future studies should work to resolve these uncertainties and more accurately account for both well users and well users affected by flooding.

Well Users Need Low-Cost Tools and Training to Effectively Implement Well Disinfection and Treatment Solutions. Few participants in this study had treatment devices that addressed microbial contamination, despite the fact that it is the contaminant of primary concern after floods and routine conditions. ${ }^{10-12,20}$ Well disinfection (i.e., shock chlorination) is an at-home, low-cost remediation solution, but results from this study raise concerns that this remediation strategy performed by residents is not effective. Materials to facilitate effective at-home treatment practices need to be developed, validated, and disseminated. Treatment solutions need to be easy for well users to implement independently and address well-specific considerations, but protocols being disseminated by government programs do not always contain the most up-to-date science ${ }^{15}$ and well users may have trouble 
performing various steps such as calculating chlorine dose. ${ }^{45,46}$ Rather than reacting after contamination events, government agencies and residents should be prepared for such events. Residents need a more holistic understanding of their well systems and resulting water quality, and a basic understanding of water quality contaminants, parameters, testing tools, and treatment alternatives. Programs like the Private Well Class (http://privatewellclass.org) and the New Hampshire Department of Environmental Services Be Well Inform Guide (https://www4.des.state.nh.us/DWITool/) are examples of programs that provide such opportunities. State and federal resources are urgently needed to ensure uniform dissemination of protective public health procedures and protocols. ${ }^{43}$

\section{ASSOCIATED CONTENT}

\section{SI Supporting Information}

The Supporting Information is available free of charge at https://pubs.acs.org/doi/10.1021/acs.est.0c07869.

Household survey and water sampling protocols; additional water testing data and information; logistic regression variables and outputs; and figures regarding microbial contamination rates (PDF)

\section{AUTHOR INFORMATION}

\section{Corresponding Authors}

Kelsey J. Pieper - Department of Civil and Environmental Engineering, Northeastern University, Boston, Massachusetts 02115, United States; (1) orcid.org/0000-0002-0273-6527; Email: k.pieper@northeastern.edu

William J. Rhoads - Department of Environmental Microbiology, Eawag-Swiss Federal Institute of Aquatic Science and Technology, 8600 Dübendorf, Switzerland; (1) orcid.org/0000-0001-9325-4680;

Email: william.rhoads@eawag.ch

\section{Authors}

C. Nathan Jones - Department of Biological Sciences, University of Alabama, Tuscaloosa, Alabama 35401, United States

McNamara Rome - Department of Civil and Environmental Engineering, Northeastern University, Boston, Massachusetts 02115, United States

Drew M. Gholson - National Center for Alluvial Aquifer Research, Mississippi State University, Stoneville, Mississippi 38776, United States

Adrienne Katner - Department of Environmental and Occupational Health Sciences, Louisiana State University Health Science Center, New Orleans, Louisiana 70112, United States

Diane E. Boellstorff - Texas A\&M AgriLife Extension Service, Department of Soil and Crop Sciences, Texas A\&M University System, College Station, Texas 77843, United States

R. Edward Beighley - Department of Civil and Environmental Engineering, Northeastern University, Boston, Massachusetts 02115, United States

Complete contact information is available at: https://pubs.acs.org/10.1021/acs.est.0c07869

\section{Notes}

The authors declare no competing financial interest.

\section{ACKNOWLEDGMENTS}

The research was supported by the National Science Foundation through a Rapid Research Response grant (\#1760296) and joint funding from Federal Emergency Management Agency (FEMA) and the Texas Division of Emergency Management (\#97036/1006700). The authors thank the Brazoria County and Houston Health Departments for providing well water testing results. The University sampling was conducted with the assistance of Chambers, Hardin, Orange, Victoria, Waller, and Wharton Counties AgriLife Extension. They also thank Drs. Marc Edwards, Terry Gentry, Leigh-Anne Krometis, and Amy Pruden for use of their laboratories, and Dr. Monty Dozier, Ryan Gerlich, Achla Om Prakash Jha, Leah Kocian, Onder Ozal, and John Smith at Texas A\&M; Maddie Brouse, Sarah Busch, Lauren Buttling, Matt Dowdle, Greg House, Sophia Lee, Kris Mapili, and Dr. Jeffrey Parks at Virginia Tech; and Aidan Battershall, PJ Bourdon, Nicole Brabant, Michael Lewis, Soha Mikdashi, Kevin Ramos, and Joseph Wanger with the Virginia Tech Corps of Cadets for their assistance in sampling preparation, collection, and analysis. Finally, the authors thank the well users who participated in this study.

\section{REFERENCES}

(1) Major Hurricane Harvey, August 25-29, National Weather Service, 2017, https://www.weather.gov/crp/hurricane_harvey (accessed Febraury 25, 2021).

(2) Governor Greg Abbott Extended The State Disaster Declaration In April 2019 For Texas Counties Affected By Hurricane Harvey; Office of the Texas Governor: Austin, TX, 2019. https://gov.texas.gov/news/ post/governor-greg-abbott-extended-the-state-disaster-declaration-inapril-2019-for-texas-counties-affected-by-hurricane-harvey (accessed Febraury 25, 2021).

(3) NGWA Offers Water Well Resources Post-Hurricane, Water Quality Products, October 31, 2017. https://www.wqpmag.com/wellwater-treatment/ngwa-offers-water-well-resources-post-hurricane (accessed Febraury 25, 2021).

(4) Region 6 Quickly Assessed Water Infrastructure after Hurricane Harvey but Can Improve Emergency Outreach to Disadvantaged Communities, Report No. 19-P-0236; U.S. Environmental Protection Agency: Washington, DC. https://www.epa.gov/sites/production/ files/2019-07/documents/_epaoig_20190716_19-p-0236.pdf (accessed Febraury 25, 2021).

(5) U.S. Environmental Protection Agency (USEPA), Private Drinking Water Wells, https://www.epa.gov/privatewells (accessed Febraury 25, 2021).

(6) Beitsch, R. Few Wells Tested for Contamination After Major Flooding From Hurricanes, The Pew Charitable Trusts. December 14, 2018. https://www.pewtrusts.org/research-and-analysis/blogs/stateline/2018/12/14/few-wells-tested-for-contamination-after-majorflooding-from-hurricanes (accessed Febraury 25, 2021).

(7) Gilliland, A.; Pieper, K.; Straif-Bourgeois, S.; Rhoads, W.; Edwards, M.; Brisolara, K.; Olexia, D.; Katner, A. Evaluation of Preparedness and Recovery Needs of Private Well Users After the Great Louisiana Flood of 2016. J. Public Health Manage. Pract. 2020, $1-11$.

(8) Kapoor, V.; Gupta, I.; Pasha, A. B. M. T.; Phan, D. Real-Time Quantitative PCR Measurements of Fecal Indicator Bacteria and Human-Associated Source Tracking Markers in a Texas River Following Hurricane Harvey. Environ. Sci. Technol. Lett. 2018, 5, 322-328.

(9) Yu, P.; Zaleski, A.; Li, Q.; He, Y.; Mapili, K.; Pruden, A.; Alvarez, P. J. J.; Stadler, L. B. Elevated Levels of Pathogenic Indicator Bacteria and Antibiotic Resistance Genes after Hurricane Harvey's Flooding in Houston. Environ. Sci. Technol. Lett. 2018, 5, 481-486. 
(10) Swistock, B. R.; Clemens, S.; Sharpe, W. E.; Rummel, S. Water Quality and Management of Private Drinking Water Wells in Pennsylvania. J. Environ. Health 2013, 75, 60-66.

(11) Pieper, K. J.; Krometis, L. A. H.; Gallagher, D. L.; Benham, B. L.; Edwards, M. Incidence of Waterborne Lead in Private Drinking Water Systems in Virginia. J. Water Health 2015, 13, 897-908.

(12) Allevi, R. P.; Krometis, L.-A. H.; Hagedorn, C.; Benham, B.; Lawrence, A. H.; Ling, E. J.; Ziegler, P. E. Quantitative Analysis of Microbial Contamination in Private Drinking Water Supply Systems. J. Water Health 2013, 11, 244.

(13) Pieper, K.; Krometis, L.; Benham, B.; Gallagher, D. Simultaneous Influence of Geology and System Design on Drinking Water Quality in Private Systems. J. Environ. Health 2016, 79, E1-E9.

(14) Invik, J.; Barkema, H. W.; Massolo, A.; Neumann, N. F.; Checkley, S. Total Coliform and Escherichia Coli Contamination in Rural Well Water: Analysis for Passive Surveillance. J. Water Health 2017, 15, 729-740.

(15) Pieper, K. J.; Rhoads, W. J.; Saucier, L.; Katner, A.; Barrett, J.; Edwards, M. Evaluating State-Level Well Disinfection Protocols in the United States. Sci. Total Environ. 2020, 720, No. 137451.

(16) Katner, A.; Pieper, K. J.; Lambrinidou, Y.; Brown, K.; Hu, C.-Y.; Mielke, H. W.; Edwards, M. A. Weaknesses in Federal Drinking Water Regulations and Public Health Policies That Impede Lead Poisoning Prevention and Environmental Justice. Environ. Justice 2016, 9, 109117.

(17) Atherholt, T. B.; Korn, L. R.; Louis, J. B.; Procopio, N. A. Repeat Sampling and Coliform Bacteria Detection Rates in New Jersey Domestic Wells. Groundwater Monit. Rem. 2015, 35, 70-80.

(18) Murphy, H. M.; McGinnis, S.; Blunt, R.; Stokdyk, J.; Wu, J.; Cagle, A.; Denno, D. M.; Spencer, S.; Firnstahl, A.; Borchardt, M. A. Septic Systems and Rainfall Influence Human Fecal Marker and Indicator Organism Occurrence in Private Wells in Southeastern Pennsylvania. Environ. Sci. Technol. 2020, 54, 3159-3168.

(19) Dai, D.; Rhoads, W. J.; Katner, A.; Strom, L.; Edwards, M. A.; Pruden, A.; Pieper, K. J. Molecular Survey of Legionella and Naegleria Fowleri in Private Wells and Premise Plumbing Following the 2016 Louisiana Flood. Environ. Sci. Water Res. Technol. 2019, 5, 14641477.

(20) Eccles, K. M.; Checkley, S.; Sjogren, D.; Barkem, H. W.; Bertazzon, S. Lessons Learned from the 2013 Calgary Flood: Assessing Risk of Drinking Water Well Contamination. Appl. Geogr. 2017, 80, 78-85.

(21) Murawski, J. The Amount of E. coli and Fecal Matter in NC Wells has Spiked Since Hurricane Florence, News and Observer. October 24, 2018. https://www.newsobserver.com/news/business/article220561095.html (accessed Febraury 25, 2021).

(22) Job, C. Responding to Flooded Wells, Water Well J., 2017. https://waterwelljournal.com/responding-flooded-wells/ (accessed Febraury 25, 2021).

(23) Van Biersel, T. P.; Carlson, D. A.; Milner, L. R. Impact of Hurricanes Storm Surges on the Groundwater Resources. Environ. Geol. 2007, 53, 813-826.

(24) John, D. E.; Rose, J. B. Review of Factors Affecting Microbial Survival in Groundwater. Environ. Sci. Technol. 2005, 39, 7345-7356. (25) Scoullos, I. M.; Lopez Vazquez, C. M.; van de Vossenberg, J.; Hammond, M.; Brdjanovic, D. Effect of Artificial Solar Radiation on the Die-Off of Pathogen Indicator Organisms in Urban Floods. Int. J. Environ. Res. 2019, 13, 107-116.

(26) American Public Health Association, American Water Works Association; Water Environment Federation In Standard Methods for Examination of Water and Wastewater, 20th ed.; American Public Health Association, Washington, D.C. 1998.

(27) Muenich, R. L.; Peel, S.; Bowling, L. C.; Haas, M. H.; Turco, R. F.; Frankenberger, J. R.; Chaubey, I. The Wabash Sampling Blitz: A Study on the Effectiveness of Citizen Science. Citzen Sci. Theory Pract. 2016, $1,3$.

(28) Hadj-Hammou, J.; Loiselle, S.; Ophof, D.; Thornhill, I. Getting the Full Picture: Assessing the Complementarity of Citizen Science and Agency Monitoring Data. PLoS One 2017, 12, No. e0188507.
(29) Texas Hurricane Harvey (DR-4332) Federal Emergency Management Agency. https://www.fema.gov/disaster/4332 (accessed Febraury 25, 2021).

(30) Smith, S. Field Evaluation of Emergency Well Disinfection for Contamination Events, Final Project Report; U.S. Federal Emergency Management Agency: Washington, DC, 2002. https://groundwaterscience.com/attachments/article/102/FEMA\%20Project\%20\%20final\%20_3.pdf (accessed Febraury 25, 2021).

(31) Ryder, P. D. Ground Water Atlas of the United States: Segment 4 Oklahoma, Texas, Hydrologic Investigations Atlas 730-E; U.S. Geological Survey: Reston, VA, 1996. https://pubs.usgs.gov/ha/ 730e/report.pdf (accessed Febraury 25, 2021).

(32) Johnson, T. D.; Belitz, K. Domestic Well Locations and Populations Served in the Contiguous U.S.: 1990. Sci. Total Environ. 2017, 607-608, 658-668.

(33) Brakenridge, G. R.; Kettner, A. J. DFO Flood Event \# 4510. Dartmouth Flood Observatory. https://floodobservatory.colorado. edu/Events/2017USA4510/2017USA4510.html (accessed Febraury $25,2021)$.

(34) Pieper, K. J.; Tang, M.; Jones, C. N.; Weiss, S.; Greene, A.; Mohsin, H.; Parks, J.; Edwards, M. A. Impact of Road Salt on Drinking Water Quality and Infrastructure Corrosion in Private Wells. Environ. Sci. Technol. 2018, 52, 14078-14087.

(35) NCHS Urban-Rural Classification Scheme for Counties Centers for Disease Control and Prevention, 2017. https://www.cdc.gov/nchs/ data access/urban rural.htm\#2013 Urban-Rural Classification Scheme_for_Counties (accessed Febraury 25, 2021).

(36) R Development Core Team, $R: A$ Language and Environment for Statistical Computing, 2012.

(37) Wickham, H.; Averick, M.; Bryan, J.; Chang, W.; McGowan, L. D. A.; François, R.; Grolemund, G.; Hayes, A.; Henry, L.; Hester, J.; Kuhn, M.; et al. Welcome to the Tidyverse. J. Open Source Software 2019, 4, No. 1686.

(38) Pebesma, E. Simple Features for R: Standardized Support for Spatial Vector Data. $R$ J. 2018, 10, 439-446.

(39) Hijmans, R. J.; Etten, J. V. Geographic Analysis and Modeling with Raster Data, R Package Version 2.0-05, 2012, https://cran.rproject.org/web/packages/raster/index.html (accessed Febraury 25, 2021).

(40) Barnier, J. J. Package 'questionr'. October 5, 2020, https://cran. r-project.org/web/packages/questionr/questionr.pdf (accessed Febraury 25,2021 )

(41) Swistock, B. R.; Sharpe, W. E. The Influence of Well Construction on Bacterial Contamination of Private Water Wells in Pennsylvania. J. Environ. Health 2005, 68, 17-22.

(42) Exner, M. E.; Spalding, R. F. Ground-Water Contamination and Well Construction in Southeast Nebraska. Groundwater 1985, 23, 26-34.

(43) Wait, K.; Katner, A.; Gallagher, D.; Edwards, M.; Mize, W.; Lee Pow Jackson, C.; Pieper, K. J. Disparities in Well Water Outreach and Assistance Offered by Local Health Departments: A North Carolina Case Study. Sci. Total Environ. 2020, 747, No. 141173.

(44) Horn, J. E.; Harter, T. Domestic Wells Have High Probability of Pumping Septic Tank Leachate. Hydrol. Earth Syst. Sci. Discuss. 2011, 8, 5701-5732.

(45) Gilliland, A. E.; Gholson, D. M.; Boellstorff, D. E.; Pieper, K. J.; Straif-Bourgeois, S.; Katner, A. Natural Disaster Emergency Response to Private Well User Needs: Evaluation of a Pilot Outreach Approach. J. Environ. Health 2020, 83, 16-24.

(46) Eykelbosh, A. J. Review of Guidelines for Shock Chlorination in Private Wells, NCCEH Evidence Reviews 2013, November, 1-11, https://www.ncceh.ca/sites/default/files/Shock_Chlorination_Wells Nov 2013 0.pdf (accessed Febraury 25, 2021).

(47) Texas Department of Licensing and Regulation, Water Well Drillers and Pump Installers Administrative Rules, https://www.tdlr.texas.gov/wwd/wwdrules.htm (accessed Febraury 25, 2021).

(48) Schumann, G.; Bates, P. D.; Horritt, M. S.; Matgen, P.; Pappenberger, F. Progress in Integration of Remote Sensing-Derived 
Flood Extent and Stage Data and Hydraulic Models Rev. Geophys. 2009, 473RG4001 DOI: 10.1029/2008RG000274.

(49) Chini, M.; Pelich, R.; Pulvirenti, L.; Pierdicca, N.; Hostache, R.; Matgen, P. Sentinel-1 InSAR Coherence to Detect Floodwater in

Urban Areas: Houston and Hurricane Harvey as a Test Case. Remote Sens. 2019, 11, No. 107. 